\title{
Photosynthesis, Chlorophyll Fluorescence, and Carbohydrate Content of Illicium Taxa Grown under Varied Irradiance
}

\author{
Jason J. Griffin, ${ }^{1}$ Thomas G. Ranney, ${ }^{2}$ and D. Mason Pharr ${ }^{3}$ \\ Department of Horticultural Science, North Carolina State University, Raleigh, NC 27695-7609
}

\begin{abstract}
AdDITIONAL INDEX wORDs. flowering anise, irradiance stress, light tolerance, mannoheptulose, photoinhibition
Aвstract. Tolerance to high solar irradiation is an important aspect of stress tolerance for landscape plants, particularly for species native to understory conditions. The objective of this study was to evaluate differential tolerance to high solar irradiation and underlying photosynthetic characteristics of diverse taxa of Illicium L. grown under full sun or $\mathbf{5 0 \%}$ shade. Eleven commercially available taxa of Illicium were evaluated for light tolerance by measuring light-saturated photosynthetic capacity $\left(\mathrm{A}_{\max }\right)$, dark-adapted quantum efficiency of photosystem II (Fv/Fm), and relative chlorophyll content using a SPAD chlorophyll meter. Comparisons of $\mathrm{A}_{\max }$ indicated that three of the 11 taxa (I. anisatum L., I. parviflorum Michx. ex Vent., and I. parviflorum 'Forest Green') maintained similar rates of light-saturated carbon assimilation when grown in either shade or full sun. All other taxa experienced a significant reduction in $A_{\max }$ when grown in full sun. Chlorophyll fluorescence analysis demonstrated that $\mathrm{Fv} / \mathrm{Fm}$ was similar between sun and shade plants for the same three taxa that were able to maintain $A_{\max }$. These taxa appeared to experience less photoinhibition than the others and maintained greater maximum photochemical efficiency of absorbed light. SPAD readings were not significantly reduced in these three taxa either, whereas most other taxa experienced a significant reduction. In fact, SPAD readings were significantly higher in I. parviflorum 'Forest Green' when grown under full sun, which also maintained the highest $A_{\max }$ of all the taxa. These results suggest that there is considerable variation in light tolerance among these taxa, with I. parviflorum 'Forest Green' demonstrating superior tolerance to high light among the plants compared. A more rigorous examination of I. parviflorum 'Forest Green' (high light tolerance) and I. floridanum Ellis (low-light tolerance) demonstrated that I. parviflorum 'Forest Green' had a considerably higher $\mathbf{A}_{\max }$, a higher light saturation point, greater potential photosynthetic capacity, reduced susceptibility to photoinhibition as indicated by superior PSII efficiency following light exposure, greater capacity for thermal de-excitation as indicated by a higher rate of nonphotochemical quenching (NPQ) under full sun, greater apparent electron transport rate (ETR) at mid-day, and higher concentrations of the free-radical scavenger myo-inositol. All of these factors contribute potentially to a greater capacity to use light energy for carbon fixation while minimizing photodamage.
\end{abstract}

Despite the necessity of light for autotrophic organisms, no plant is capable of using $100 \%$ of maximum solar irradiation for photosynthesis (Demming-Adams et al., 1997). When irradiance exceeds that which can be used for photochemistry, other protective mechanisms must be used to dissipate excess excitation energy or damage will occur.

Most plants have the ability to acclimate to a specific light environment. Chlorophyll concentration, Calvin cycle intermediates, chloroplast density, and carotenoid composition have all been reported to fluctuate during the acclimation process (Demmig-Adams et al., 1997). Understory plants grown in relatively high light typically have the ability to increase maximum, lightsaturated, photosynthetic capacity $\left(\mathrm{A}_{\max }\right)$ as well as other energy dissipating mechanisms. Likewise, $\mathrm{A}_{\max }$ of pioneer species grown under a low-light environment can be suppressed (Kitao et al., 2000). Ramalho et al. (2000) demonstrated that a 15-d exposure to high light slightly elevated $\mathrm{A}_{\max }$, and more than doubled the irradiance required to reach $\mathrm{A}_{\max }$ in $\mathrm{CO}_{2}$ saturated leaves of Coffea

Received for publication 18 Dec. 2002. Accepted for publication 8 Aug. 2003. This research was funded in part by the North Carolina Agricultural Research Service, Raleigh, NC 27695-7643. The authors wish to thank Stuart L. Warren for providing field space to conduct these experiments, William M. Reece for technical assistance, and Felix Keller for critical discussion during the soluble carbohydrate identification and quantification. From a dissertation submitted by J.J.G. in partial fulfillment of the requirements for the $\mathrm{PhD}$ degree.

${ }^{1}$ Assistant professor and corresponding author. Current address: Kansas State University, John C. Pair Horticultural Center, Haysville, KS 67060-8351.

${ }^{2}$ Professor.

${ }^{3}$ William Neal Reynolds distinguished professor. arabica L. 'Catuaní' (coffee), indicating the presence of alternative dissipation mechanisms.

The capacity of a plant to use and dissipate light energy is a function of both genotype and environmental conditioning. Pioneer species and species that typically grow in exposed locations usually have a greater light-saturated $\mathrm{A}_{\max }$ than understory species (Lambers et al., 1998). Therefore, a larger percentage of absorbed energy is used in photosynthesis, reducing the need for alternative dissipating mechanisms, and minimizing the risk of photodamage. However, when grown in shade, understory species typically have a higher quantum yield $(\Phi)$ and greater $\mathrm{A}_{\max }$ than pioneer species (Kitao et al., 2000).

Shade-grown plants often have relatively large antenna complexes for maximum light capture (Lambers et al., 1998). When exposed to high irradiance, the energy absorbed by these relatively large light-capturing complexes can be detrimental to the plant if not efficiently dissipated. Even plants that have been grown under high light conditions can experience supraoptimal irradiance. When this occurs, photoinhibition, or a decrease in quantum efficiency of photosystem II (PSII), can be significant (Demmig-Adams et al., 1998; Kitao et al., 2000; Schindler and Lichtenthaler, 1996). Therefore, the ability of a plant to acclimate to high irradiance and elevate $\mathrm{A}_{\max }$ could be a highly successful mechanism to hasten nondamaging energy dissipation.

The ratio of variable fluorescence to maximal fluorescence (Fv/Fm) of dark-adapted leaves is used commonly to assess the relative state of PSII. Fv/Fm is used frequently as an expression of photoinhibition (Critchley, 1998, Kitao et al., 2000; Krause 
et al., 1999; Schansker and van Rensen, 1999). Additionally, photoinhibition is typically associated with, but not necessarily accompanied by, chlorophyll degradation and a reduction of $\mathrm{A}_{\max }$ (Bumann and Oesterhelt, 1995; Critchley, 1998; Demmig-Adams et al., 1998). Excess absorbed energy can result in destruction of chlorophyll, causing an overall yellowing of the foliage. A rapid method to evaluate relative chlorophyll concentrations in leaves of plants grown under varying light regimes might be an effective method for the evaluation of high light tolerance. Species tolerant of high light are able to maintain high concentrations of chlorophyll when grown in a high light environment. Chlorophyll meters (e.g., SPAD-502, Minolta Corp., Ramsey, N.J.) can be useful tools for estimating chlorophyll content and monitoring foliar nitrogen content (Monje and Bugbee, 1992; Rodriguez and Miller, 2000; Sibley et al., 1996; Yadava, 1986). In addition, chlorophyll meters can be used to provide an objective value of leaf greenness compared to a subjective visual rating. When interpreted in combination with light saturated $A_{\max }$ and quantum efficiency of PSII, the relative chlorophyll concentration (or greenness) of leaves could provide supporting evidence in assigning light tolerance to various species.

The genus Illicium (anise tree) consists of broad-leaved evergreen shrubs and small trees that are native to tropical and subtropical regions of Asia and southeastern North America (Smith, 1947). Plants generally exist as part of the understory on moist sites, and have therefore become a popular landscape plant for low-light situations. However, when planted in a high-irradiance location, many taxa of Illicium show symptoms of stress, such as leaf chlorosis and necrosis. Although typically not lethal, the aesthetic value is severely reduced and thus the plant's value in the landscape is diminished. A better understanding of light tolerance among these taxa would aid in selection and improvement of these plants for varied light environments. Previous work with Illicium (Olsen et al., 2002) suggests that there is a range of light tolerance within the genus. Illicium parviflorum had a high photosynthetic capacity in high light, whereas I. floridanum and I. anisatum were significantly reduced. The study also revealed I. henryi was intolerant of high light and all plants died in full sun. However, only a limited number of taxa were investigated, and plants were grown in small containers.

The first objective of this research was to evaluate and compare a greater diversity of taxa of Illicium for light tolerance by evaluating $\mathrm{A}_{\max }$ dark-adapted $\mathrm{Fv} / \mathrm{Fm}$, and relative chlorophyll content of plants grown under different irradiance. The second objective was to compare and contrast the photochemical light use of two selected taxa. One species was chosen for its ability to grow successfully in a high light environment and one species was selected for its apparent inability to grow in high light.

\section{Materials and Methods}

\section{Experiment 1}

Rooted stem cuttings of 11 taxa of Illicium (Table 1) were transplanted into 18-L containers filled with a substrate of 8 pine bark : 1 sand (by volume) amended with dolomitic limestone at $1.2 \mathrm{~kg} \cdot \mathrm{m}^{-3}$ and topdressed with $127 \mathrm{~g}$ of $23 \mathrm{~N}-1.7 \mathrm{P}-6.6 \mathrm{~K}$ Osmocote Pro controlled release fertilizer (Scotts-Sierra Hort. Products Co., Marysville, Ohio). On 25 May 2000, containers were placed on a gravel nursery production pad at the Horticultural Field Laboratory, North Carolina State University, Raleigh. Plants were placed in full sun or under shade structures covered by woven shade cloth excluding $50 \%$ incident irradiance. All plants were irrigated daily with sufficient water to maintain a minimum leaching fraction of $25 \%$.

On 14 July 2000, data collection began. This date allowed sufficient time for acclimation and production of new leaves in their respective light environment. By this date, some of the fullsun plants were beginning to show symptoms of stress. Leaves chosen for all measurements were newly formed, fully expanded, and representative of the given plant.

Net PHOtosynthesis. Net photosynthesis $\left(\mathrm{P}_{\mathrm{n}}\right)$ measurements were conducted on a block-by-block basis on sunny days between the hours of 0900 and 1200 HR using a CIRAS-1 (PP Systems, Haverhill, Mass.) infrared gas analyzer modified with a temperature and light controlled cuvette. Preliminary measurements indicated that before 0900 and after $1200 \mathrm{HR}$, stomatal conductance was limited and carbon assimilation was unusually low across all taxa. All plants were exposed to 15 min of full sunlight to allow for stomatal opening before taking measurements. The sample leaf was then placed in the cuvette that was maintained at $27^{\circ} \mathrm{C}$ and exposed to $2000 \mu \mathrm{mol} \cdot \mathrm{m}^{-2} \cdot \mathrm{s}^{-1}$ photosynthetically active radiation (PAR) and an ambient $\mathrm{CO}_{2}$ concentration of $350 \mu \mathrm{L} \cdot \mathrm{L}^{-1}$. Once stomatal conductance and $\mathrm{CO}_{2}$ assimilation stabilized, data were recorded. When inside the cuvette, all sampled leaves were exposed to identical environmental conditions. Allowing sufficient time to pass in the cuvette ensured photosynthetic rates were more related to physiological factors and plant acclimation than metabolic dif-

Table 1. Light saturated photosynthetic capacity $\left(\mathrm{A}_{\max }\right)$, quantum efficiency of dark-adapted leaves (Fv/Fm), and relative chlorophyll content (SPAD units) of 11 different taxa of Illicium grown under $50 \%$ shade (shade) or full solar irradiance (sun) (Expt.1).

\begin{tabular}{|c|c|c|c|c|c|c|}
\hline \multirow[b]{2}{*}{ Taxa } & \multicolumn{2}{|c|}{$\begin{array}{c}\mathrm{A}_{\max } \\
\left(\mu \mathrm{mol} \cdot \mathrm{m}^{-2} \cdot \mathrm{s}^{-1}\right) \\
\end{array}$} & \multicolumn{2}{|c|}{$\mathrm{Fv} / \mathrm{Fm}$} & \multicolumn{2}{|c|}{$\begin{array}{l}\text { Chlorophyll } \\
\text { (SPAD units) }\end{array}$} \\
\hline & Sun & Shade & Sun & Shade & Sun & Shade \\
\hline I. anisatum $\mathrm{L}$. & 11.4 & 13.4 & 0.82 & 0.84 & 58 & 60 \\
\hline I. floridanum Halleys Comet & $12.6 \mathrm{~b}$ & $15.0 \mathrm{a}$ & 0.79 & 0.82 & 54 & 59 \\
\hline I. floridanum Head's Compact & $10.1 \mathrm{~b}$ & $13.5 \mathrm{a}$ & $0.72 b$ & $0.79 \mathrm{a}$ & 44 & 48 \\
\hline I. floridanum Semmes & $11.3 \mathrm{~b}$ & $14.0 \mathrm{a}$ & $0.73 \mathrm{~b}$ & $0.80 \mathrm{a}$ & $49 \mathrm{~b}$ & $57 \mathrm{a}$ \\
\hline I. lanceolatum Smith & $6.6 \mathrm{~b}$ & $9.6 \mathrm{a}$ & 0.81 & 0.83 & $54 \mathrm{~b}$ & $60 \mathrm{a}$ \\
\hline I. mexicanum Smith Aztec Fire & $9.4 \mathrm{~b}$ & $13.3 \mathrm{a}$ & $0.76 \mathrm{~b}$ & $0.81 \mathrm{a}$ & $48 \mathrm{~b}$ & $59 \mathrm{a}$ \\
\hline I. parviflorum Michx. ex Vent. & 14.1 & 14.3 & 0.82 & 0.83 & 58 & 58 \\
\hline I. parviflorum Forest Green & 17.7 & 17.6 & 0.82 & 0.83 & $63 \mathrm{a}$ & $56 \mathrm{~b}$ \\
\hline I. $\times$ Woodland Ruby & $10.6 \mathrm{~b}$ & $16.0 \mathrm{a}$ & 0.79 & 0.82 & $53 \mathrm{~b}$ & $64 \mathrm{a}$ \\
\hline
\end{tabular}


ferences related to varying leaf temperatures associated with sun and shade leaves.

Chlorophyll Fluorescence. Dark-adapted quantum efficiency of open PSII reaction centers $[(\mathrm{Fm}-\mathrm{Fo}) / \mathrm{Fm}$ or Fv/Fm] was measured on each plant on 20 July 2000 after sunset. Chlorophyll fluorescence was measured using a pulse-modulated fluorometer (OS-500, OptiScience, Tyngsboro, Mass.) providing a modulating irradiance of $3.6 \mu \mathrm{mol} \cdot \mathrm{m}^{-2} \cdot \mathrm{s}^{-1} P A R$ followed by a $0.8 \mathrm{~s}$ saturating pulse of $1800 \mu \mathrm{mol} \cdot \mathrm{m}^{-2} \cdot \mathrm{s}^{-1} P A R$.

SPAD MEASUEMENTS. Relative chlorophyll content of each taxa was determined using a chlorophyll meter (Minolta SPAD-502). One SPAD meter reading was taken on each of three recently expanded leaves, near the distal portion of the stem, that were typical in appearance for each plant. The readings were taken half-way between the mid vein and leaf margin at the widest portion of the leaf. These three readings were averaged for a single SPAD reading for that plant. This procedure was repeated three consecutive days during the first week of July 2000, and the three averaged SPAD readings were used for statistical analysis.

The experimental design was a randomized complete block $(n=6)$ with a split plot arrangement of treatments. Two light regimes (100\% and $50 \%$ of full sunlight) represented the whole plots, while the split plot units consisted of the 11 taxa (Table 1). Each shade structure was large enough to provide adequate shade for an entire block of 11 shaded plants. Data were subjected to ANOVA and, where appropriate, means were separated with a protected LSD at $P \leq 0.05$ (SAS Institute Inc., Cary, N.C.).

\section{Experiment 2}

In the Fall 2000, plants were pruned to remove the most recent flush of growth and over-wintered, outside, under a layer of protective white plastic. In Spring 2001, the containerized plants were again placed randomly in full sun or under $50 \%$ shade as described previously. Growing conditions were similar for those described in Expt. 1. Beginning in early July, after plants had produced new growth and acclimated to their environment, data were collected only on I. parviflorum 'Forest Green' and I. floridanum. These two taxa were selected for further analyses based on their apparent tolerance and intolerance to exposure to full sun, respectively.

Light RESPONSE CURVES. Light response curves were generated on a block-by-block basis for each plant. An entire block of plants was moved into a greenhouse the evening before the day measurements were to be taken. Light response curves were generated the following day for each plant in random order. A recently matured leaf was placed in a dark cuvette at $30^{\circ} \mathrm{C}$, supplied with $\mathrm{CO}_{2}$ at $350 \mu \mathrm{L} \cdot \mathrm{L}^{-1}$, and given 15 min to stabilize. Dark respiration was then recorded and the irradiance was increased to $2000 \mu \mathrm{mol} \cdot \mathrm{m}^{-2} \cdot \mathrm{s}^{-1}$ PAR in nine increments $(50,100,150,200$, $500,800,1000,1500$, and $\left.2000 \mu \mathrm{mol} \cdot \mathrm{m}^{-2} \cdot \mathrm{s}^{-1}\right)$. Assimilation was recorded at each light level following a $10 \mathrm{~min}$ acclimation period. Data were fit to the model equation $A=\Phi Q+A_{\max }-[\sqrt{ }(\Phi Q+$ $\left.\left.A_{\max }\right)^{2}-\left(4 \Phi Q k A_{\max }\right)\right] /(2 k)-R_{\text {day }}$ as given by Lambers et al. (1998) where I is the rate of assimilation, $\Phi$ is the apparent quantum efficiency, $Q$ is the incident irradiance, $A_{\max }$ is assimilation rate at light saturation, $\mathrm{k}$ is the parameter for convexity, and $R_{\text {day }}$ is the rate of dark respiration.

A/Ci curves. Following light response curves, A/Ci curves (photosynthesis plotted against intercellular $\mathrm{CO}_{2}$ concentration) were generated to investigate specific characteristics of photosynthesis and to estimate potential photosynthetic capacity. Another recently matured leaf was placed in the cuvette at a
$\mathrm{CO}_{2}$ concentration of $370 \mu \mathrm{L} \cdot \mathrm{L}^{-1}, 30{ }^{\circ} \mathrm{C}$, and $1000 \mu \mathrm{mol} \cdot \mathrm{m}^{-2} \cdot \mathrm{s}^{-1}$ PAR. The air within the cuvette was maintained at $\approx 70 \%$ relative humidity to minimize stomatal heterogeneity. Following a 15 min acclimation period, $\mathrm{P}_{\mathrm{n}}$ was recorded and the $\mathrm{CO}_{2}$ concentration was reduced to $50 \mu \mathrm{L} \cdot \mathrm{L}^{-1}$ and another reading was taken. A gradual increase in ambient $\mathrm{CO}_{2}$ to a final concentration of 2000 $\mu \mathrm{L} \cdot \mathrm{L}^{-1}$ in 10 increments $(50,100,150,250,370,500,800,1200$, 1500 , and $2000 \mu \mathrm{L} \cdot \mathrm{L}^{-1}$ ) occurred with a reading taken at each increment following a $10 \mathrm{~min}$ acclimation period. Data were then fit to the exponential model used by Jacob et al. (1995) and adopted by Reid and Fiscus (1998): $A=a\left(1-e^{-b C i}\right)+c$, where $a$ is the potential photosynthetic capacity, $b$ is the initial slope or carboxylation efficiency, $c$ is the intercept on the ordinate, and $\mathrm{Ci}$ is the estimated intercellular $\mathrm{CO}_{2}$ concentration.

Chlorophyll Fluorescence. Dark-adapted Fv/Fm measurements were taken as described in Expt. 1, only these measurements were predawn. Shade grown plants were then moved to full sun for the remaining measurements to monitor how they responded to excessive irradiance. Light adapted chlorophyll fluorescence measurements were taken at 0800, 1000, 1200, 1400, and 1600 $\mathrm{HR} t$ the natural leaf angle. The fluorometer fiberoptic was placed at a $60^{\circ}$ angle to the leaf blade and positioned so as not to shade the leaf surface. Following exposure to a modulating light of 3.6 $\mu \mathrm{mol} \cdot \mathrm{m}^{-2} \cdot \mathrm{s}^{-1}$ PAR, a $0.8 \mathrm{~s}$ saturating pulse of $1800 \mu \mathrm{mol} \cdot \mathrm{m}^{-2} \cdot \mathrm{s}^{-1}$ PAR was applied to the leaf. Light adapted steady state fluorescence yield $\left(F^{\prime}\right)$ and maximum light adapted fluorescence yield $\left(F^{\prime}\right)$ were recorded by the fluorometer. From the data, actual light adapted PSII efficiency $\left[\left(\mathrm{Fm}^{\prime}-\mathrm{F}^{\prime}\right) / \mathrm{Fm}^{\prime}\right.$ or $\left.\Delta \mathrm{F} / \mathrm{Fm}^{\prime}\right]$, nonphotochemical quenching (NPQ) $[(\mathrm{Fm}-\mathrm{Fm}$ ')/Fm'], and apparent photosynthetic electron transport rate $(\mathrm{ETR})[(\Delta \mathrm{F} / \mathrm{Fm}) \times(\mathrm{PAR}) \times(0.5) \times(0.84)]$ were calculated using the fluorometer's on-board program.

Chlorophyll content. Leaf discs were collected in early morning from recently matured leaves with a $1.0 \mathrm{~cm}$ diameter cork borer. Chlorophyll was extracted by placing three discs $\left(2.36 \mathrm{~cm}^{2}\right)$ in $8.0 \mathrm{~mL} \mathrm{~N}, \mathrm{~N}$ '-dimethylformamide (DMF) in the dark at room temperature on a rotary shaker for $48 \mathrm{~h}$. Chlorophyll (Chl) a and $\mathrm{b}$ were determined spectrophotometrically using the wavelengths and equations of Porra et al. (1989).

Carbohydrate analysis. Five or six recently matured leaves were removed from each plant in early morning and immediately frozen at $-80^{\circ} \mathrm{C}$. Frozen leaf tissue was lyophilized and ground to pass a 40 -mesh $(0.635-\mathrm{mm})$ screen. For each plant sample, $200 \mathrm{mg}$ of ground tissue was placed in a $15 \mathrm{~mL}$ centrifuge tube and suspended in $3 \mathrm{~mL}$ of $80 \%$ aqueous ethanol. The slurry was incubated at $80^{\circ} \mathrm{C}$ for $5 \mathrm{~min}$ then centrifuged at $1000 \mathrm{~g}_{\mathrm{n}}$ for $10 \mathrm{~min}$. The extraction was repeated two more times and the supernatant combined after each. Pooled extracts were evaporated at $45^{\circ} \mathrm{C}$ under vacuum and oven dried overnight at $70^{\circ} \mathrm{C}$. The residue was dissolved in $1.0 \mathrm{~mL}$ of deionized, distilled water and soluble sugars analyzed by high-performance liquid chromatography (HPLC). The HPLC system (described by Prata et al., 1997) was equipped with a guard column (C-18 Corasil, Bio-Rad, Hercules, Calif.) and in-line cation and anion guards (Micro-Guard, Bio-Rad). Carbohydrates were separated on a column $\left(\mathrm{Ca}^{++}\right.$Carbohydrate column, Sierra Separations, Inc., Sparks, Nev.) with a flow rate of $0.4 \mathrm{~mL} \cdot \mathrm{min}^{-1}$ water at $75^{\circ} \mathrm{C}$. Carbohydrate identity and quantity were analyzed using a differential refractometer (Model 410, Waters/Millipore, Milford, Mass.) coupled to a computing integrator (Model SP4200, Spectra Physics, San Jose, Calif.) and compared with carbohydrate standards.

The experimental design was a randomized complete block $(n=6)$ with a split plot arrangement of treatments. Two light 
regimes (100\% and $50 \%$ of full sunlight) represented the whole plots, while I. floridanum and I. parviflorum 'Forest Green' made up the split plot units. The light response curves, $\mathrm{A} / \mathrm{Ci}$ curves, $\Delta \mathrm{F} / \mathrm{Fm}$ ', and ETR were analyzed as a split-split plot with incident light (light response curves), intercellular $\mathrm{CO}_{2}$ concentration (A/ $\mathrm{Ci})$, or time of day $(\Delta \mathrm{F} / \mathrm{Fm}$ ' and ETR $)$ as the sub-subplot. Data were subjected to ANOVA and, where appropriate, means were separated with a protected LSD at $P \leq 0.05$. Appropriate models were fit to the data using PROC NLIN in SAS (SAS Institute Inc., Cary, N.C.).

\section{Results}

\section{Experiment 1}

Net photosynthesis. An interaction was observed between light environment and taxa for $\mathrm{A}_{\max }(P=0.02) . \mathrm{P}_{\mathrm{n}}$ of plants grown in full sun was significantly less in all but three taxa (Table 1), two of which were cultivars of the same species (I. anisatum, I. parviflorum, and I. parviflorum 'Forest Green'). A ${ }_{\max }$ for sun and shade grown plants of I. parviflorum and I. parviflorum 'Forest Green' were nearly identical $\left(\approx 14.2\right.$ and $17.6 \mu \mathrm{mol} \cdot \mathrm{m}^{-2} \cdot \mathrm{s}^{-1}$, respectively), whereas assimilation rates for all other taxa grown in full sun were at least $2 \mu \mathrm{mol} \cdot \mathrm{m}^{-2 \cdot} \cdot \mathrm{s}^{-1} \mathrm{CO}_{2}$ less than their sun grown counterparts.

Among the shade grown plants, I. parviflorum 'Forest Green' $\left(17.6 \mu \mathrm{mol} \cdot \mathrm{m}^{-2} \cdot \mathrm{s}^{-1}\right)$ and $I . \times$ 'Woodland Ruby' $\left(16.0 \mu \mathrm{mol} \cdot \mathrm{m}^{-2} \cdot \mathrm{s}^{-1}\right)$ had the highest $\mathrm{A}_{\max }$. Conversely, I. lanceolatum $\left(9.6 \mu \mathrm{mol} \cdot \mathrm{m}^{-2} \cdot \mathrm{s}^{-1}\right)$ and $I$. henryi $\left(10.9 \mu \mathrm{mol} \cdot \mathrm{m}^{-2} \cdot \mathrm{s}^{-1}\right)$ had the lowest $\mathrm{A}_{\max }$ when grown in shade. Of all the I. floridanum taxa, I. floridanum 'Halley's Comet' had the highest $\mathrm{A}_{\max }$.

The relative $A_{\max }$ among the sun-grown plants followed a similar trend with a few exceptions. Illicium parviflorum 'Forest Green' $\left(17.7 \mu \mathrm{mol} \cdot \mathrm{m}^{-2} \cdot \mathrm{s}^{-1}\right)$ still had the greatest assimilation rate, but was followed by the unnamed clone of I. parviflorum (14.1 $\left.\mu \mathrm{mol} \cdot \mathrm{m}^{-2} \cdot \mathrm{s}^{-1}\right)$. While $\mathrm{A}_{\max }$ of shade grown $I . \times$ 'Woodland Ruby' was relatively high, assimilation in the sun grown plants was reduced considerably (16.0 and $10.6 \mu \mathrm{mol} \cdot \mathrm{m}^{-2} \cdot \mathrm{s}^{-1}$, respectively). As was true with the shade plants, I. floridanum 'Halley's Comet' retained the highest $\mathrm{A}_{\max }$ for the taxa of I. floridanum.

CHLOROPHYLl FLUORESCENCE. There was an interaction between taxa and exposure for dark-adapted Fv/Fm measurements taken after sundown between taxa and light environment $(P=0.0001)$. Plants grown under conditions of high light had reduced $\mathrm{Fv} / \mathrm{Fm}$ in some, but not all, taxa (Table 1). With the exception of I. mexicanum 'Aztec Fire', where Fv/Fm was reduced by high light, the only taxa that were significantly reduced by high irradiance were clones of I. floridanum. The only taxon of I. floridanum that was not affected was I. floridanum 'Halley's Comet', the same taxon that was able to maintain a relatively high $\mathrm{A}_{\max }$. Overall, I. floridanum was affected the greatest by high light, indicating some degree of photoinhibition in high light.

RELATIVE CHLOROPHYLL CONTENT. SPAD measurements indicated that many of the taxa with a low $\mathrm{A}_{\max }$ also had low SPAD readings (Table 1). Illicium floridanum had the lowest relative chlorophyll content. The three taxa that were able to maintain a high $\mathrm{A}_{\max }$ also maintained high chlorophyll content. Of all the taxa, only I. parviflorum 'Forest Green' increased chlorophyll content when grown under high light.

Plants grown in full sun were visually distinct from those grown in 50\% shade. Although data were not collected, plants grown in full sun appeared to have shorter internodes, reduced leaf size, and leaves were frequently chlorotic with marginal necrosis. Leaves of I. parviflorum and I. parviflorum 'Forest Green', however, displayed no symptoms of chlorosis or necrosis, assumed a vertical orientation when grown in full sun, and a horizontal orientation in the shade. A similar trend was observed with I. anisatum. However, none of the other taxa displayed this morphological characteristic.

\section{Experiment 2}

LIGHT RESPONSE CURVES. The light response curves revealed no difference in photosynthesis between plants of the same species grown in full sun or under shade, so only the main effects of species are presented (Fig. 1). The data clearly revealed a fundamental difference between these two species. Illicium parviflorum 'Forest Green' had a substantially higher light-saturated photosynthetic rate than I. floridanum. Predicted $\mathrm{A}_{\max }$ of I. parviflorum 'Forest Green' and I. floridanum was 23 and $7 \mu \mathrm{mol} \cdot \mathrm{m}^{-2} \cdot \mathrm{s}^{-1} \mathrm{CO}_{2}$, respec-

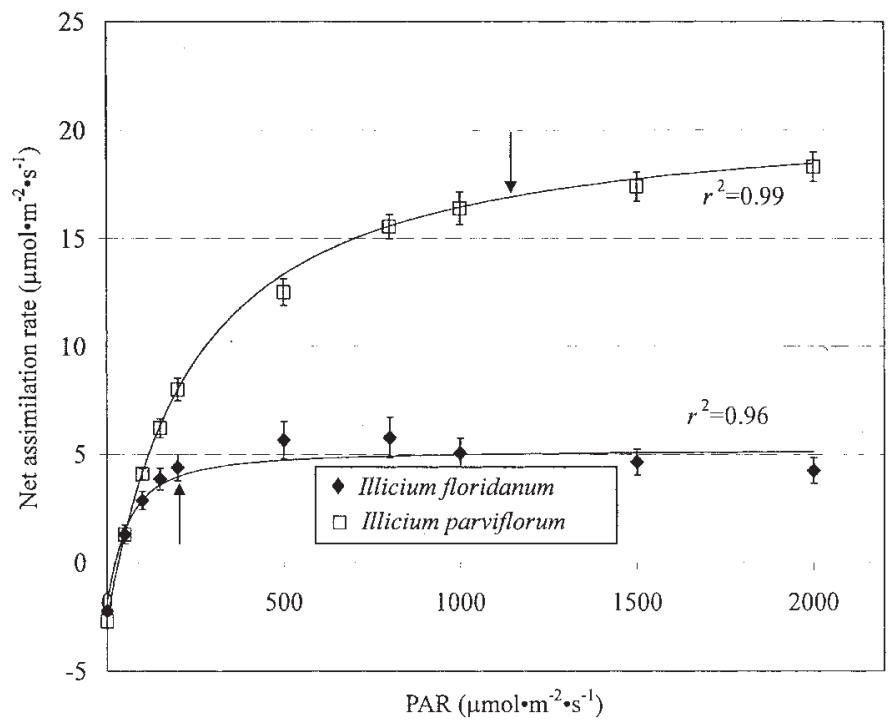

Fig. 1. Light response curves for Illicium floridanum and I. parviflorum 'Forest Green' (Expt. 2). Data averaged over light environment within a taxon. $\mathrm{CO}_{2}$ concentration $=350 \mu \mathrm{L} \cdot \mathrm{L}^{-1}$, leaf temperature $=30^{\circ} \mathrm{C}$. Arrows represent light saturation point for I. floridanum and I. parviflorum 'Forest Green' (200 and $1170 \mu \mathrm{mol} \cdot \mathrm{m}^{-2} \cdot \mathrm{s}^{-1} P A R$, respectively). Vertical bars $= \pm 1 \mathrm{sE}, \mathrm{n}=12$. Data fit to the model proposed by Lambers et al. (1998).

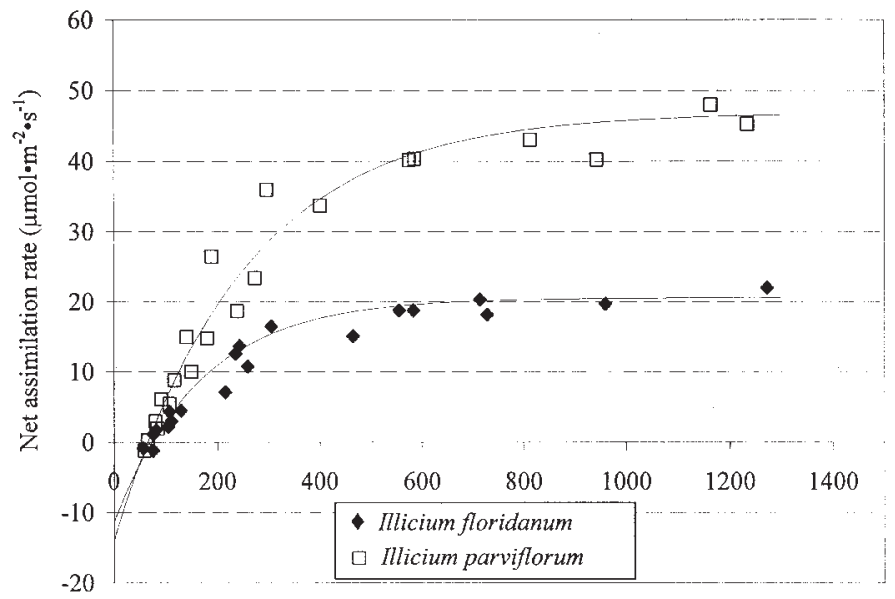

Intercellular $\mathrm{CO}_{2}$ concentration $\left(\mu \mathrm{L} \cdot \mathrm{L}^{-1}\right)$

Fig. 2. A/Ci curves for Illicium floridanum and I. parviflorum 'Forest Green' (Expt. 2). Data averaged over light environment within a taxon and fit to the model proposed by Jacob et al. (1995). Leaf temperature $=30^{\circ} \mathrm{C}$, irradiance $=1000 \mu \mathrm{mol} \cdot \mathrm{m}^{-2} \cdot \mathrm{s}^{-1}$. 
tively. Surprisingly, no differences between the two species were detected for quantum efficiency, the light compensation point, or the rate of respiration (data not shown). However, the light saturation point was more than 5-fold greater for I. parviflorum 'Forest Green' than I. floridanum (1170 and $200 \mu \mathrm{mol} \cdot \mathrm{m}^{-2 \cdot} \cdot \mathrm{s}^{-1}$ PAR, respectively).

A/Ci Curves. The data from the A/Ci curves suggest that the difference in photosynthetic capacity between the two species was not entirely due to stomatal aperture. Although stomatal conductance was less in I. floridanum (data not presented), it was still sufficient to reach a saturating internal $\mathrm{CO}_{2}$ concentration (Fig. 2). Based on the model, a predicted potential photosynthetic capacity of $56 \mu \mathrm{mol} \cdot \mathrm{m}^{-2} \cdot \mathrm{s}^{-1} \mathrm{CO}_{2}$ for I. parviflorum 'Forest Green' compared to $24 \mu \mathrm{mol} \cdot \mathrm{m}^{-2} \cdot \mathrm{s}^{-1} \mathrm{CO}_{2}$ for I. floridanum was calculated. Similar to the light response curves, the predicted maximum rate of photosynthesis was the only parameter measured that differed between the two species. Neither carboxylation efficiency nor the rate of respiration differed (data not shown).

Chlorophyll Fluorescence. Dark-adapted Fv/Fm of $I$. parviflorum 'Forest Green' in sun or shade grown plants was found to be in a range typical of many species that are not stressed $(0.80$

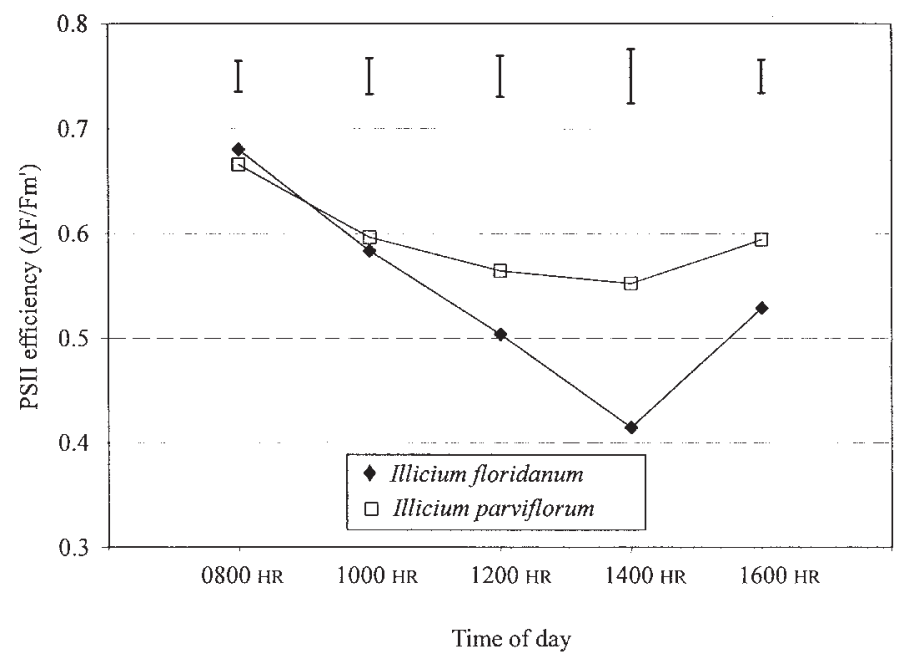

Fig. 3. Actual PSII efficiency $\left(\Delta \mathrm{F} / \mathrm{Fm}^{\prime}\right)$ of Illicium floridanum and I. parviflorum 'Forest Green' during the course of a sunny day (Expt. 2). Data averaged over light environment within a taxon. Vertical bars $= \pm 1$ SE of all data collected at that time, $\mathrm{n}=12$.

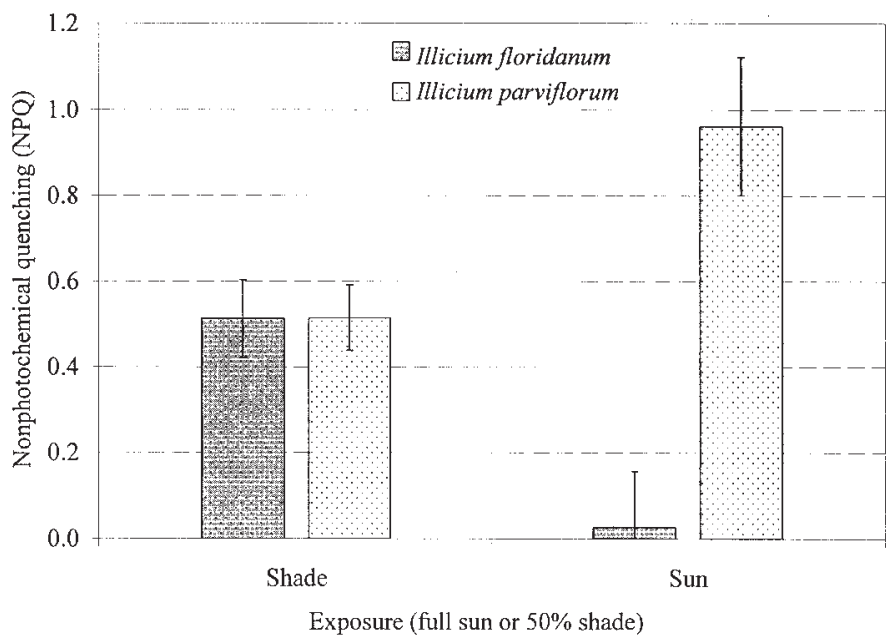

Fig. 4. Nonphotochemical quenching of Illicium floridanum and I. parviflorum 'Forest Green' averaged over the course of a day (Expt. 2). Vertical lines = \pm 1 SE, $\mathrm{n}=30$. \pm 0.009 and $0.82 \pm 0.004$, respectively) (Bjorkman and Demmig, 1987). However, Fv/Fm of shade grown I. floridanum was significantly less $(0.71 \pm 0.03)$ and was even further reduced in the sun grown plants $(0.47 \pm 0.08)$. Actual PSII efficiency $(\Delta \mathrm{F} / \mathrm{Fm} ')$ was also affected by the increasing solar intensity throughout the day (Fig. 3). In both species, $\Delta \mathrm{F} / \mathrm{Fm}$ ' was reduced during the middle part of the day followed by a slight recovery in afternoon. However, the decrease for I. floridanum was much greater than it was for I. parviflorum 'Forest Green'. Of greater significance, perhaps, is the response of NPQ. In I. parviflorum 'Forest Green', an $88 \%$ increase in NPQ was observed from shade- to sun-grown plants $(0.51 \pm 0.08$ and $0.96 \pm 0.16$, respectively), compared to a $94 \%$ decrease when that same comparison is made in I. floridanum $(0.51 \pm 0.09$ and $0.03 \pm 0.13$, respectively) (Fig. 4). The time of day effect was similar for the two species and light treatments, so the values were averaged and only the main effect of time is presented. NPQ was relatively low at $1000 \mathrm{HR}(0.18 \pm 0.14)$, rising to a high at $1400 \mathrm{HR}(0.69 \pm 0.17)$, before decreasing at 1600 HR $(0.44 \pm 0.12)$.

Light treatment did not affect ETR within a species $(P=0.86)$; however, there were differences between the two species $(P=$ 0.02) (Fig. 5). While ETR for both species was relatively similar through $1000 \mathrm{HR}$, at $1200 \mathrm{HR}$ ETR of I. floridanum had reached its maximum observed rate. The rate for I. parviflorum 'Forest Green', however, continued to increase and reached its maximum at $1400 \mathrm{HR}$ before beginning to decline. The maximum rate was $\approx 100 \mu \mathrm{mol} \cdot \mathrm{m}^{-2} \cdot \mathrm{s}^{-1}$ greater in I. parviflorum 'Forest Green' than I. floridanum.

Chlorophyll content. Total chlorophyll content, chl a, and the ratio chl a:b did not significantly change among the species or treatments (Table 2). However, chl b, the primary chlorophyll constituent of the light harvesting antennae, was significantly higher in shade-grown I. floridanum than in all other plants and treatments, indicating a species by treatment interaction.

SOLUble CARbOHYDRATE CONCENTRATION. Carbohydrate analysis revealed different patterns of sugar production in these two species (Table 3 ). While both species produced the raffinose family oligosaccharides (RFOs) stachyose and raffinose, I. floridanum contained twice as high a concentration of RFOs as I. parviflorum 'Forest Green'. The proportion of those two sugars in relation to each other was also different. Raffinose was the primary oli-

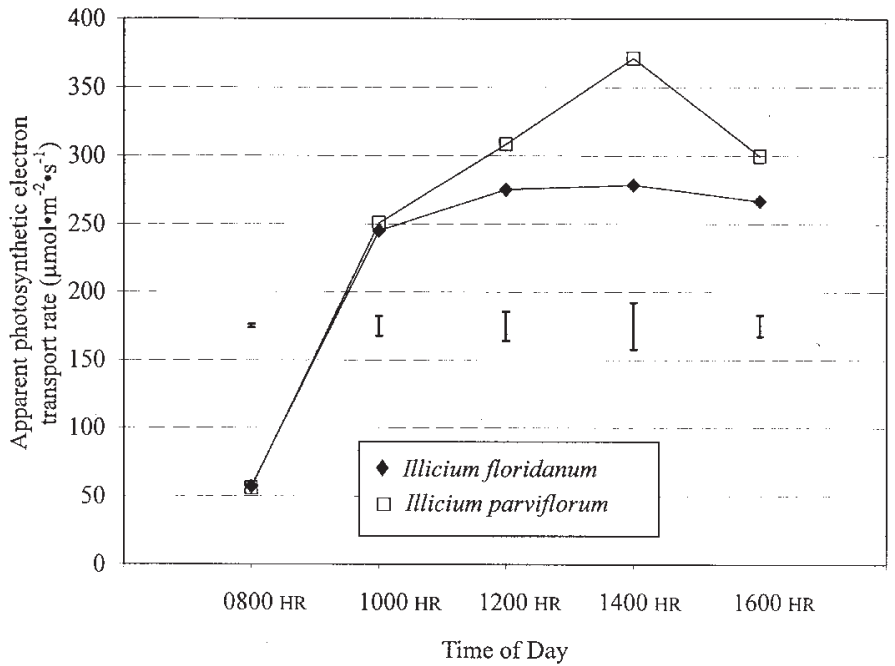

Fig. 5. Apparent photosynthetic electron transport rate (ETR) of Illicium floridanum and I.parviflorum 'Forest Green' (Expt. 2). Data averaged over light environment. Vertical bars $= \pm 1$ SE of all data collected at that time, $n=12$. 
Table 2. Chlorophyll content of Illicium floridanum and I. parviflorum 'Forest Green' grown in full solar irradiance (sun) or under $50 \%$ shade (shade) (Expt. 2).

\begin{tabular}{lcccc}
\hline & \multicolumn{4}{c}{ Chlorophyll content $\left(\mu \mathrm{g} \cdot \mathrm{cm}^{-2}\right)$} \\
\cline { 2 - 5 } Species/treatment & Chl a & Chl b & Total & $\mathrm{a}: \mathrm{b}$ \\
\hline I. floridanum/shade & 64 & $24 \mathrm{a}^{\mathrm{z}}$ & 88 & 2.8 \\
I. floridanum/sun & 51 & $16 \mathrm{~b}$ & 67 & 3.3 \\
I. parviflorum/shade & 54 & $18 \mathrm{~b}$ & 72 & 3.0 \\
I. parviflorum/sun & 52 & $17 \mathrm{~b}$ & 69 & 3.1 \\
ANOVA & $\mathrm{NS}$ & $* *$ & $\mathrm{NS}$ & $\mathrm{NS}$
\end{tabular}

${ }^{2}$ Mean separation within a column where appropriate by Fisher's Protected LSD at the $P=0.05$ level; $\mathrm{n}=6$.

ss,**Nonsignificant or significant at $P<0.01$, respectively.

Table 3. Leaf tissue soluble carbohydrate content $\left(\mu \mathrm{g} \cdot \mathrm{g}^{-1}\right.$ dry weight) of Illicium floridanum and I. parviflorum 'Forest Green' grown under full solar irradiance (sun) or $50 \%$ shade (shade) (Expt. 2).

\begin{tabular}{lrrrrr} 
& \multicolumn{2}{c}{ I. floridanum } & & \multicolumn{2}{c}{ I. parviflorum } \\
\cline { 5 - 6 } Soluble & Sun & Shade & & Sun & Shade \\
\cline { 2 - 3 } \cline { 5 - 6 } Stachyose & $85 \mathrm{~b}^{\mathrm{z}}$ & $73 \mathrm{~b}$ & & $313 \mathrm{a}$ & $259 \mathrm{a}$ \\
Raffinose & $1417 \mathrm{a}$ & $1252 \mathrm{~b}$ & & $458 \mathrm{c}$ & $368 \mathrm{c}$ \\
Sucrose & $947 \mathrm{~b}$ & $918 \mathrm{~b}$ & & $1304 \mathrm{a}$ & $1153 \mathrm{a}$ \\
Galactinol & $0 \mathrm{~b}$ & $0 \mathrm{~b}$ & & $407 \mathrm{a}$ & $351 \mathrm{a}$ \\
Glucose & $0 \mathrm{~b}$ & $0 \mathrm{~b}$ & & $212 \mathrm{a}$ & $185 \mathrm{a}$ \\
Myo-inositol & $151 \mathrm{c}$ & $171 \mathrm{c}$ & & $284 \mathrm{a}$ & $213 \mathrm{~b}$ \\
Mannoheptulose & $1271 \mathrm{~b}$ & $1838 \mathrm{a}$ & & $71 \mathrm{c}$ & $47 \mathrm{c}$ \\
Total & $3872 \mathrm{a}$ & $4252 \mathrm{a}$ & & $3050 \mathrm{~b}$ & $2576 \mathrm{c}$ \\
\hline
\end{tabular}

${ }^{2}$ Mean separation within rows by Fisher's Protected LSD, $P<0.05 ; \mathrm{N}=6$.

gosaccharide in I. floridanum, whereas the difference in content between the two sugars was minimal in I. parviflorum 'Forest Green'. Sucrose appeared to be the primary sugar in leaves of $I$. parviflorum 'Forest Green', and its concentration was unaffected by sun or shade in either species. Both galactinol and glucose were absent in I. floridanum but present in I. parviflorum 'Forest Green'. As with sucrose, their concentration was unaffected by sun or shade treatments. The seven-carbon sugar, mannoheptulose was also detected in these plants. Interestingly, it was a dominant soluble carbohydrate in I. floridanum, yet a small component in I. parviflorum 'Forest Green'. Additionally, its concentration was higher in shade-grown I. floridanum, whereas the growing environment did not affect concentration in I. parviflorum 'Forest Green'. The remaining soluble carbohydrate detected in these plants was the polyol, myo-inositol. Its content was higher in $I$. parviflorum, and sun-grown plants of this taxa contained greater amounts than shade-grown plants.

\section{Discussion}

Sun-tolerant and light-acclimated plants typically have a higher $\mathrm{A}_{\max }$ when exposed to high light than do sun-intolerant plants (Lambers et al., 1998). The results presented herein, comparing high to low light acclimated plants, indicate that among the taxa tested, $I$. anisatum, I. parviflorum, and I. parviflorum 'Forest Green' were the most sun tolerant. $\mathrm{A}_{\max }$ for these taxa was unaffected when grown under full solar irradiance, whereas $\mathrm{A}_{\max }$ for all other taxa was significantly reduced in the high light environment (Table 1), which is characteristic of photoinhibition. The majority of tested taxa were not able to acclimate and increase $\mathrm{A}_{\max }$ in the high light environment. These results differ only slightly from those recently reported by Olsen et al. (2002) who found a reduction in $\mathrm{A}_{\max }$ in all tested taxa, including I. anisatum and I. parviflorum 'Forest Green'. Previous research found that I. anisatum had a significant ability to increase its light saturated $A_{\max }$ rate in response to high light while growing in its natural environment with an unrestricted root zone (Kusumoto, 1957). This would suggest that soil volume is an important factor in overall plant stress and may be a confounding factor in previous reports where small containers $(2.8 \mathrm{~L})$ were used (Olsen et al., 2002). In the current study, plants were grown in $18 \mathrm{~L}$ containers, which may have overcome the adverse effects associated with root restriction. It was also reported by Kusumoto (1957) that respiration and the light compensation point were significantly greater in high light acclimated plants, another characteristic of plants that have acclimated to a high light environment (Lambers et al., 1998).

Further investigation of $I$. parviflorum 'Forest Green' and $I$. floridanum revealed substantial differences in photosynthetic characteristics. As illustrated in Fig. 1, I. parviflorum 'Forest Green' was able to assimilate three times more $\mathrm{CO}_{2}$ than I. floridanum at a saturating irradiance. Olsen et al. (2002) also reported that $I$. parviflorum 'Forest Green' attained a greater $\mathrm{A}_{\max }$ than I. floridanum 'Pebblebrook' under high irradiance. This ability to use a greater portion of the absorbed light energy to assimilate a significantly greater amount of carbon may lower the amount of excess energy and thereby reduce the extent of photoinhibition. Whereas others have reported a decrease in full sun (Olsen et al., 2002), in the current study $\mathrm{A}_{\max }$ did not vary as a result of growth in sun or shade in Expt. 2. This may suggest that these species have little ability to acclimate to higher levels of irradiance. It is worth noting that these plants were grown outside, where $50 \%$ shade can still exceed $1000 \mu \mathrm{mol} \cdot \mathrm{m}^{-2} \cdot \mathrm{s}^{-1} P A R$ during early afternoon. This level is rarely achieved in growth chambers, yet often a lesser irradiance is used as a 'high light' treatment throughout the literature. In the current study, $50 \%$ shade may have been sufficient to elicit a high irradiance acclimation without inducing photoinhibition from excess irradiance, thereby masking many of the differences between sunand shade-grown plants. Unlike $\mathrm{A}_{\max }$, there were no differences in quantum efficiency or the light compensation point between these two species, suggesting that at low irradiance the two are equally efficient in using absorbed light. The light saturation point, however, was significantly higher for I. parviflorum 'Forest Green' than for I. floridanum. Again, indicating that I. parviflorum 'Forest Green' is able to use a greater portion of sunlight in photosynthesis than I. floridanum.

The higher photosynthetic capacity of I. parviflorum 'Forest Green' was confirmed by the A/Cicurves (Fig. 2). Even at saturating concentrations of $\mathrm{CO}_{2}$, I. parviflorum 'Forest Green' assimilated twice as much carbon as I. floridanum. There was no difference between the sun- and shade-grown plants, indicating that the physiological capacity to assimilate $\mathrm{CO}_{2}$ is not affected by the different light environments in which these plants were grown. The data also suggest that at low concentrations of $\mathrm{CO}_{2}$ there was no difference in the efficiency or the rate that carbon was assimilated, only that $I$. floridanum becomes $\mathrm{CO}_{2}$ saturated at a lower ambient concentration. As $\mathrm{CO}_{2}$ concentration increased, the higher photosynthetic capacity allowed I. parviflorum 'Forest Green' to continue assimilating carbon whereas I. floridanum could not.

Chlorophyll fluorescence is used frequently to determine the state of energy distribution in the thylakoid membrane, the quantum efficiency of PSII, and the extent of photoinhibition (Björkman and Demmig-Adams, 1994; Critchley, 1998; Maxwell and Johnson, 2000). Plants subjected to high-irradiance stress, typically have 
lower Fv/Fm values than nonstressed plants (Björkman and Demmig, 1987). The data presented herein indicate when Fv/Fm was significantly reduced by the high light environment, a reduction in $A_{\max }$ was also observed in that taxon (Table 1). Likewise, the three taxa that maintained $A_{\max }$ in high light, also maintained similar values of $\mathrm{Fv} / \mathrm{Fm}$. Under high irradiance, the transfer of absorbed energy becomes particularly important because excess energy can lead to the formation of reactive oxygen species, a prime cause of photoinhibition (Critchley, 1998; Schansker and van Rensen, 1999). Quantum efficiency of four taxa in this study was decreased by high light (Table 1). These taxa also displayed symptoms associated with photoinhibition such as reduced chlorophyll content and necrotic regions of the leaf.

In the second phase of this research, apparent quantum efficiency of PSII in I. parviflorum 'Forest Green' was unaffected by growing environment, indicating no significant photoinhibition in this species. In I. floridanum, however, Fv/Fm of the shade-grown plants was significantly lower than in I. parviflorum 'Forest Green', and exposure to full sun caused a further reduction in Fv/Fm. This was similar to the response that was observed in Expt. 1. Such a response is frequently reported for stressed plants. It is often interpreted that the applied stress has caused significant damage to PSII, and has reduced the efficiency of absorbed light energy transfer from the light-harvesting complex to PSII (Bilger and Björkman, 1990; Maxwell and Johnson, 2000; Ranney and Peet, 1994). Light adapted $\Delta \mathrm{F} / \mathrm{Fm}$ ' was also unaffected by growth in full sun or shade within a species (Fig. 3). However, the two species differed from each other throughout the course of the day. PSII efficiency decreased as the day progressed in both species eventually reaching a minimum at $\approx 1400$ HR, when photoinhibition would be most likely. However, the decrease in I. floridanum was more severe, suggesting inferior tolerance to high irradiance. A similar trend was also noted by Demmig-Adams et al. (1998) who reported a severe decrease in PSII efficiency as the day progressed in shade leaves of Schefflera arboricola (Hayata) Merrill (schefflera). These data, combined with the $\mathrm{Fv} / \mathrm{Fm}, \mathrm{A} / \mathrm{Ci}$ response curves, and light response curves, indicate that $I$. floridanum is unable to process as much absorbed light energy into photosynthesis as I. parviflorum 'Forest Green'. Species that are adapted to or acclimated to high irradiance have a greater level of nonphotochemical quenching (NPQ) than species that are considered light sensitive or not acclimated to high irradiance. There were no statistical differences in NPQ through the course of the day. However, total NPQ averaged over all times showed significant differences (Fig. 4). Whereas NPQ in I. parviflorum 'Forest Green' increased from shade- to sun-grown plants, NPQ in the sun-grown plants of I. floridanum was significantly less than the shade-grown plants, indicating an inability to dissipate excess energy thermally. Additionally, the higher ETR in I. parviflorum 'Forest Green' is further evidence that this species has a higher photochemical capacity in high light conditions (Fig. 5). This information indicates the potential for considerable photoinhibition in the leaves of I. floridanum.

Typically, shade-grown plants have higher chlorophyll concentrations per unit area than sun-grown plants. SPAD readings of I. anisatum, I. parviflorum, and I. parviflorum 'Forest Green', the same three taxa that were able to maintain $A_{\max }$ in high light, were not reduced by high light. In fact, SPAD readings for $I$. parviflorum 'Forest Green' actually increased in response to the increased irradiance suggesting an increased concentration of chlorophyll. This characteristic is common among light tolerant species (Lambers et al., 1998), yet is opposite of previous reports (Olsen et al., 2002). Limited soil volume, and therefore increased plant stress, may account for the different observations in the two studies. Illicium floridanum 'Halley's Comet' and I. floridanum 'Heads Compact' maintained similar chlorophyll content in shade and high light. It is not surprising that I. floridanum 'Halley's Comet' was not affected since it was the most tolerant of all the I. floridanum taxa, and Fv/Fm in this taxon was not affected by high light. Although SPAD readings for I. × 'Woodland Ruby' and I. lanceolatum were both significantly reduced by high light, the diminished level was still similar to those plants where no reduction was observed. Interestingly, these two taxa showed no decrease in $\mathrm{Fv} / \mathrm{Fm}$ due to the high light either, indicating the reduced $\mathrm{A}_{\max }$ may be due to some other physiological factor.

When actual chlorophyll content was measured in the second phase of this study, only chl b was affected by treatments, and it was highest in I. floridanum grown in the shade. Chl b is most abundant in the antennae of the light harvesting complex, whereas chl a is concentrated around PSII. To capture as much light as possible, shade-grown plants typically have more lightharvesting complexes per unit area than do sun-grown plants that typically receive more light than needed. Therefore, it was not surprising that the chl b content was higher in the shade-grown plant. What was surprising was that shade-grown I. parviflorum 'Forest Green' did not have more chl b than the sun-grown plants. In light of the lack of physiological differences between sun- and shade-grown plants with regard to photosynthesis and chlorophyll fluorescence, perhaps species of Illicium, similar to I. parviflorum 'Forest Green', do not normally adjust chlorophyll content in response to irradiance. A previous report also noted no change in total chlorophyll content in I. parviflorum 'Forest Green' grown in sun or shade (Olsen et al., 2002). Alternatively, 50\% shade may have been sufficient to elicit a high light acclimation. If this is the case, the decrease in chl b content in I. floridanum could be an indication of chlorophyll destruction by excess irradiance. This theory is reinforced by the dramatic reduction of NPQ in sun-grown I. floridanum, a process that occurs in the light-harvesting complex. These two sets of data suggest that in sun-grown $I$. floridanum there is a dramatic reduction in the concentration of light harvesting complexes and thus a reduction of chl b.

The soluble carbohydrate profile of these plants was both complex and unusual. Both species contained a substantial amount of RFOs, but I. floridanum contained significantly more. Although $I$. floridanum contained abundant RFOs, there was no free glucose, galactinol, or fructose present in the leaves, suggesting that the galactosyl transferase in this species was sufficient to prevent an accumulation of the substrates. Sucrose was the soluble sugar of greatest content in I. parviflorum 'Forest Green' and was significantly greater than in I. floridanum. This is a logical sequence given the higher level of RFOs in I. floridanum. If I. parviflorum 'Forest Green' produced a similar amount of RFOs, the sucrose content would have to fall to a similar level as I. floridanum. Myo-inositol, present in both species, was greater in content in I. parviflorum 'Forest Green'. This carbohydrate had been implicated previously in scavenging reactive oxygen species, which is a critical defense against excess irradiance. Additionally, the amount of myo-inositol was greatest in I. parviflorum 'Forest Green' that had been grown in full sun, suggesting that its content may be affected by sun exposure. Perhaps most intriguing was the presence of the seven-carbon sugar, mannoheptulose. While the production of this carbohydrate is well documented in Persea americana Miller (avocado), its occurrence elsewhere is not well known. The presence of mannoheptulose in these two species of Illicium varies considerably. In I. floridanum, mannoheptulose 
contributed to $33 \%$ and $43 \%$ of soluble carbohydrates in sun- and shade-grown plants, respectively. That compared to only $2 \%$ in leaves of I. parviflorum 'Forest Green', regardless of sun exposure. However, mannoheptulose is a competitive inhibitor of hexokinase, an enzyme that represses gene expression. Therefore, the physiological significance of mannoheptulose as well as its cellular localization in Illicium remains to be elucidated. The production of mannoheptulose in $P$. americana occurs by the condensation of dihydroxyacetone phosphate (three-carbon) with erythrose-4phosphate (four-carbon) to form sedoheptulose-1,7-bisphosphate (seven-carbon) which is then isomerized to a phosphorylated Dmannoheptulose (Liu et al., 2002). All the above are intermediates in the photosynthetic carbon reduction cycle and raise the question as to whether the accumulation of mannoheptulose acts as a sink interfering with adequate recycling of ribulose-1,5-bisphosphate in I. floridanum.

These results demonstrate there is a wide range of tolerance to high irradiance among taxa of Illicium. Light saturated $\mathrm{A}_{\max }$ varied considerably among the taxa and, in general, was lower in sun-grown plants than shade-grown plants. However, not all taxa experienced a decreased $\mathrm{A}_{\max }$ in full sun. Of the tested taxa, I. parviflorum and I. parviflorum 'Forest Green' appeared to be the most light tolerant. Their superior rate of photosynthesis in both high irradiance and $50 \%$ shade suggests that photoinhibition was minimal in this species. The results reported by Olsen et al. (2002) also support this theory. Illicium anisatum also maintained a statistically similar light-saturated $\mathrm{A}_{\max }$ in both sun- and shade-grown plants. Other taxa such as I. floridanum, I. henryi, and I. lanceolatum, with lower rates of light-saturated photosynthesis, were more likely to encounter excess irradiance and therefore experience significant over-excitation of the photosystem.

Although I. floridanum is one of the more popular taxa in commercial production, these plants were intolerant of the high light environment. When compared to I. parviflorum 'Forest Green', chlorophyll fluorescence analysis revealed I. floridanum had reduced $\triangle \mathrm{F} / \mathrm{Fm}$ ', NPQ, and ETR characteristics, suggesting photoinhibition during peak daily irradiance may play a role in the reduced light-saturated $\mathrm{A}_{\max }$ and potential photosynthetic capacity. Although most of the taxa did not perform well in full sun, there is some tolerance to high irradiance in this genus. Both clones of $I$. parviflorum withstood full sunlight with no signs of photoinhibition or any adverse effects of the high irradiance.

\section{Literature Cited}

Bilger, W. and O. Björkman. 1990. Role of the xanthophyll cycle in photoprotection elucidated by measurements of light-induced absorbance changes, fluorescence and photosynthesis in leaves of Hedera canariensis. Photosyn. Res. 25:173-185.

Björkman, O. and B. Demmig. 1987. Photon yield of $\mathrm{O}_{2}$ evolution and chlorophyll fluorescence characteristics at $77 \mathrm{~K}$ among vascular plants of diverse origins. Planta 170:489-504.

Björkman, O. and B. Demmig-Adams. 1994. Regulation of photosynthetic light energy capture, conversion, and dissipation in leaves of higher plants, p. 17-47. In: E.D. Schulze and M.M. Caldwell (eds.). Ecophysiology of photosynthesis. Ecological studies. vol. 100. Springer-Verlag, New York.

Bumann, D. and D. Oesterhelt. 1995. Destruction of a single chlorophyll is correlated with the photoinhibition of photosystem II with a transiently inactive donor side. Proc. Natl. Acad. Sci. USA 92:12195-12199.

Critchley, C. 1998. Photoinhibition, p. 264-272. In: A.S. Raghavendra (ed.). Photosynthesis: A comprehensive treatise. Cambridge Univ. Press. Cambridge, United Kingdom.

Demmig-Adams, B., W.W. Adams, III, and S.C. Grace. 1997. Physiology of light tolerance in plants. Hort. Rev. 18:215-246.

Demmig-Adams, B., D.L. Moeller, B.A. Logan, and W.W. Adams, III. 1998. Positive correlation between levels of retained zeaxanthin + antheraxanthin and degree of photoinhibition in shade leaves of Schefflera arboricola (Hayata) Merrill. Planta 205:367-374.

Jacob, J., C. Greitner, and B.G. Drake. 1995. Acclimation of photosynthesis in relation to Rubisco and non-structural carbohydrate contents and in situ carboxylase activity in Scirpus olneyi at elevated $\mathrm{CO}_{2}$ in the field. Plant Cell Environ. 18:875-884.

Kitao, M., T.T. Lei, T. Koike, H. Tobita, and Y. Maruyama. 2000. Susceptibility to photoinhibition of three deciduous broadleaf tree species with different successional traits raised under various light regimes. Plant Cell Environ. 23:81-89.

Krause, G.H., N. Carouge, and H. Garden. 1999. Long-term effects of temperature shifts on xanthophyll cycle and photoinhibition in spinach (Spinacia oleracea). Austral. J. Plant Physiol. 26:125-134.

Kusumoto, T. 1957. Physiological and ecological studies on the plant production in plant communities. Bot. Mag. 70:299-304.

Lambers, H., F.S. Chapin, III, and T.L. Pons. 1998. Plant physiological ecology. Springer-Verlag, New York.

Liu, X., J. Sievert, M. Arpaia, and M.A. Madore. 2002. Postulated physiological roles of the seven-carbon sugars, mannoheptulose, and perseitol in avocado. J. Amer. Soc. Hort. Sci. 127:108-114.

Maxwell, K. and G.N. Johnson. 2000. Chlorophyll fluorescence-A practical guide. J. Expt. Bot. 51:659-668.

Monje, O.A. and B. Bugbee. 1992. Inherent limitations of nondestructive chlorophyll meters: A comparison of two types of meters. HortScience 27:69-71.

Olsen, R.T., J.M. Ruter, and M.W. Rieger. 2002 Photosynthetic responses of container-grown Illicium L. taxa to sun and shade. J. Amer. Soc. Hort. Sci. 127:919-924.

Porra, R.J., W.A. Thompson, and P.E. Kriedemann. 1989. Determination of accurate extinction coefficients and simultaneous equations for assaying chlorophylls $a$ and $b$ extracted with four different solvents: Verification of the concentration of chlorophyll standards by atomic absorption spectroscopy. Biochim. Biophys. Acta 975:384-394.

Prata, R.T.N., J.D. Williamson, M.A. Conkling, and D.M. Pharr. 1997. Sugar repression of mannitol dehydrogenase activity in celery cells. Plant Physiol. 114:307-314.

Ramalho J.C., T.L. Pons, H.W. Groeneveld, H.G. Azinheira, and M.A. Nunes. 2000. Photosynthetic acclimation to high light conditions in mature leaves of Coffea arabica L.: Role of xanthophylls, quenching mechanisms and nitrogen nutrition. Austral. J. Plant Physiol. 27: 43-51.

Ranney, T.G. and M.M. Peet. 1994. Heat tolerance of five taxa of birch (Betula): Physiological responses to supraoptimal leaf temperatures. J. Amer. Soc. Hort. Sci. 119:243-248.

Reid, C.D. and E.L. Fiscus. 1998. Effects of elevated $\left[\mathrm{CO}_{2}\right]$ and/or ozone on limitations to $\mathrm{CO}_{2}$ assimilation in soybean (Glycine max). J. Expt. Bot. 49:885-895.

Rodriguez, I.R. and G.L. Miller. 2000. Using a chlorophyll meter to determine the chlorophyll concentration, nitrogen concentration, and visual quality of St. Augustinegrass. HortScience 35:751-754.

Schansker, G. and J.J.S. van Rensen. 1999. Performance of active photosystem II centers in photoinhibited pea leaves. Photosyn. Res. 62:175-184.

Schindler, C. and H.K. Lichtenthaler. 1996. Photosynthetic $\mathrm{CO}_{2}$-assimilation, chlorophyll fluorescence and zeaxanthin accumulation in field grown maple trees in the course of a sunny and a cloudy day. J. Plant Physiol. 148:399-412.

Sibley, J.L., D.J. Eakes, C.H. Gilliam, G.J. Keever, W.A. Dozier, Jr., and D.G. Himelrick. 1996. Foliar SPAD-502 meter values, nitrogen levels, and extractable chlorophyll for red maple selections. HortScience 31: 468-470.

Smith, A.C. 1947. The families Illiciaceae and Schisandraceae. Sargentia $7: 1-224$.

Yadava, U.L. 1986. A rapid and nondestructive method to determine chlorophyll in intact leaves. HortScience 21:1449-1450. 